\title{
Ankle Arthroscopy in Talar Osteoid Osteoma treatment: A case report
}

\author{
Tran Trung Dung 1,4,5, Dao Xuan Thanh 1,2,5, Hoang Gia Du1,2, Duong Dinh Toan ${ }^{1,3}$, Dinh Ngoc Son ${ }^{1,3}$, Le Manh Son $^{1,3}$, \\ Nguyen Hoang Long ${ }^{1,3}$, Bui Van Giang ${ }^{1,4}$, Nguyen Huy Phuong ${ }^{1,4,5}$, Do Van Minh ${ }^{1,5}$
}

\begin{abstract}
We report the case of a female patient, 13 years old, with an osteoid osteoma of the left talar neck. The tumor was arthroscopically removed. Pathological examination confirmed the diagnosis of osteoid osteoma. Preoperative, the patient had severe pain in the ankle joint, walked lame, and was unresponsive to pain relief medicines, even Aspirin. Post-operative, there was immediate and complete pain relief and the patient remains asymptomatic after 06 weeks.
\end{abstract}

Keywords: osteoid osteoma, talus, ankle arthroscopy

\section{CASE REPORT}

A 13-year-old female patient Chu Thanh H. at Lang Giang, Bac Giang, VietNam was taken to the Orthopedic department - St. Paul Hospital to be examined and consulted due to pain in the left ankle, walking lame. The disease started 8 months ago. Initially, the patient had acute pain in the left ankle. Then the pain spread to the leg and thigh, with increased severity. The pain was greatest at night from 11 p.m to 3 a.m. The pain was intermittent, each occurrence lasting about 1 hour. Painkiller did not help, and the pain level increase.

After that, the patient was taken to the Central hospital for Pediatrics to be examined and treated. Here, doctors prescribed to take X-ray and CT on left ankle and detected a cyst at the talus. The patient was operated with medial side of left ankle joint incision to remove bone cyst. However, the pain state is still not improved post-operative. After discharging, the patient was examined at another hospital. The patient took Aspergic with lbuprofen, the pain was reduced but after only a few hours, she got severe pain. At St. Paul Hospital, we examined the patient who had no fever, severe pain in the left ankle, walking lame and using crutches. Pressure at the mid ankle fold caused much pain.

On the CT film of left ankle (Figure 1), we found a circular lesion of approximately $1 \mathrm{~cm}$ diameter at the talar neck, close to under the arthrodial cartilage surface. The center of the cyst is the nidus that is approximately $0.3 \times 0.5 \mathrm{~cm}$ in size, the surrounding is radiolucent area and the outside is the sclerotic bone.

On the MRI film of ankle joint (Figure 2), we saw decreased signal image on T1 due to the bone marrow edema surrounding the tumor and increased signal on $\mathrm{T} 2$.

We realized this is a fairly typical case of osteoid osteoma, both clinically as well as radiologically and we decided to conduct ankle arthroscopy to remove the tumor. Left ankle arthroscopy was conducted with 2 portals located medial and lateral to the ankle joint's anterior. In addition, we added 1 extra minor portal, mid-ankle joint for easily operating, with an incision at each portal that is approximately $0.5 \mathrm{~cm}$. When entering the joint after cleaning the inflamed synovial membrane tissue, by exploring the whole ankle joint, we detected the abnormal position of the talar articular neck

\footnotetext{
1 Hanoi Medical University, Hanoi, Vietnam

2 Bachmai University Hospital, Hanoi, Vietnam

3 Vietduc University Hospital, Hanoi, Vietnam

4 Saint Paul University Hospital, Hanoi, Vietnam

5 Hanoi Medical University Hospital, Hanoi, Vietnam
}

Correspondence: Tran Trung Dung

Hanoi Medical University, Hanoi, Vietnam

Received: 13 Sep 2018, Accepted: 29 Oct 2018

(C) 2019 by the authors; licensee Modestum Ltd., UK. This article is an open access article distributed under the terms and conditions of the Creative Commons Attribution License (http://creativecommons.org/licenses/by/4.0/). 


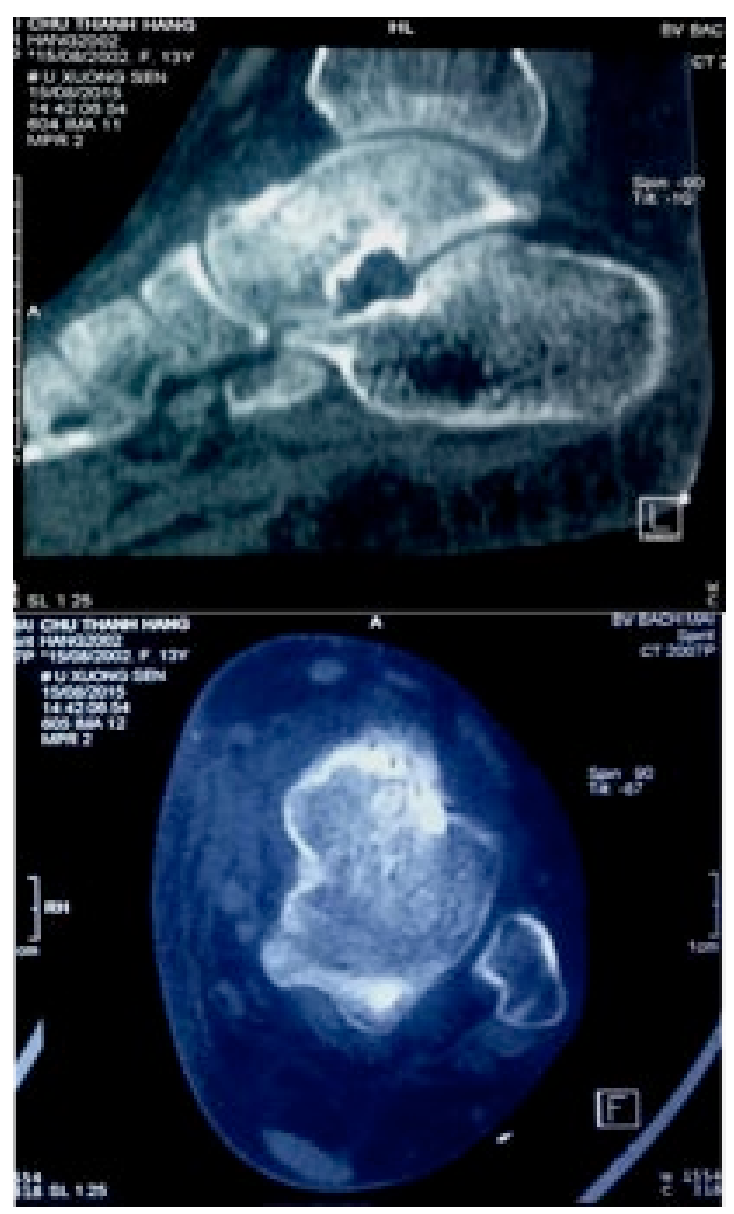

Figure 1: CT film of the left ankle

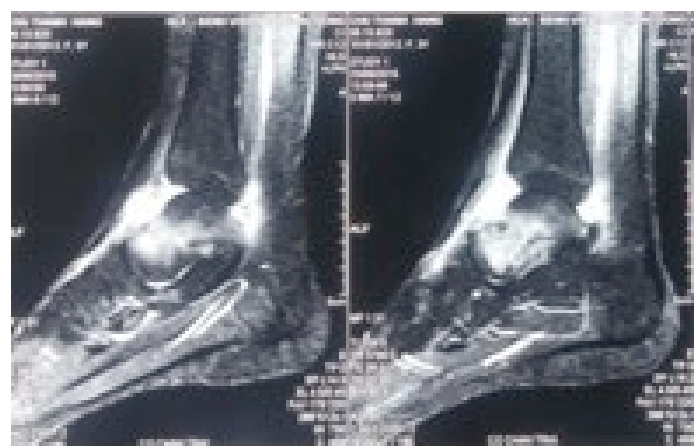

Figure 2: MRI film of the left ankle joint

surface corresponding to the suspected location on the CT film and the MRI film. After purifying the abnormal articular cartilage at the talar neck, the tumor is exposed with the nidus in the central region (Figure 3).

The tumor was removed by Curet and endoscopic instruments until the normal bone tissue. Check the remaining areas of the ankle did not see the other injuries. We then washed the joint and stitched the incision. The patient was instructed on late leg pressing post-operative.

On the first day after surgery, the patient slept well, complete pain free. The post-operative CT film showed the tumor was removed (Figure 4).

The patient is discharged after 3 days, gets late left leg pressing, walks by crutches and periodic re-examines by appointment. The post-operative anapath result is accordance with the preoperative diagnosis of osteoid osteoma. 


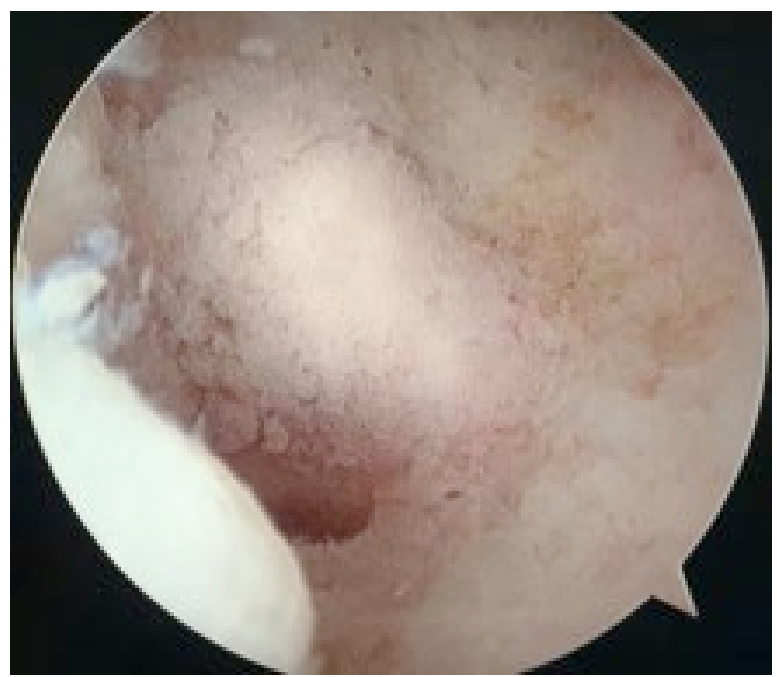

Figure 3: The tumor is exposed with the nidus in the central region

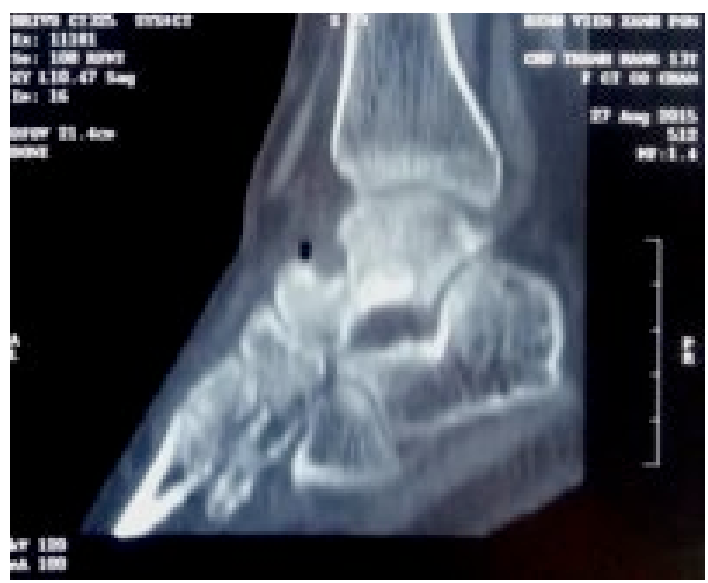

Figure 4: Post-operative CT film

\section{DISCUSSION}

Osteoid osteoma is a quite special injury, accounting for about $12 \%$ of benign bone tumors $(1,2)$. The appearance of tumors in the talus is very rare and consequently can be diagnosed late. According to statistics by Snow et al. (5) for 05 patients with osteoid osteoma in the talus diagnosis took an average of 2.5 years. The diagnosis of this disease should be considered when symptoms of chronic ankle joint pain; however, image diagnosis is not always typical. In this case, a combined capsular-type lesion at the talus may cause the diagnosis, the decision of surgery and the incision at the previous hospital to become inaccurate. They operated to open medial side of the ankle, interfered with the cyst of talar medial face without being able to reach the osteoid osteoma at the talar neck's anterior side - the main cause of severe pain of the patient. The patient came to us with a disease history of about 8 months, with typical clinical symptoms of the osteoid osteoma disease namely: much pain in the ankle joint; increased pain at night and when walking; analgesic response when treated with low dose aspirin; normal systemic symptoms. However, the image of the tumor on the Xray is quite faint, the primary diagnostic imaging is on $C T$ film with typical lesion which is the nidus in the center of the tumor, the surrounding is radiolucent area, the outside is the sclerotic bone (Figure 1) and on MRI is decreased signal image on T1 due to the bone marrow edema surrounding the tumor and increased signal on T2 (Figure 2). Some researchers have shown that $\mathrm{MRI}$ is a more sensitive image diagnosis method than $\mathrm{CT}$ though $\mathrm{CT}$ produces more specific images of osteoid osteoma (6-12).

There are many different options in the indication for treatment. Operative by direct incision into ankle joint anterior face that was often chosen before. The requirement of surgery is to completely remove the tumor. Osteoid osteoma, however, is usually very small, in this case the size of the tumor on CT film is only about $0.3 \times 0.5 \mathrm{~cm}$. If operating, it will be very difficult to identify the tumor and has to remove plenty of around normal bone tissues that weakening the structure of talar neck, slowing down the recovery process, perhaps even causing talus fracture. In addition, the tumor is 
located close to and under the talar articular neck surface. There is a passage into the joint and talar articular surface quite lame on CT film and MRI film that was a suggestion for us to decide on ankle arthroscopy to remove the tumor. This surgery has been described in several reports by foreign authors (13-20); however, this is the first domestic report.

After the endoscope into the ankle joint, with an endoscope in lateral portal and manipulation tools in medial portal, we explored the whole ankle joint and detected the abnormal position of talar articular neck surface corresponding to the suspected location on the CT film and the MRI film. The tumor was exposed and removed not too difficultly. About quite featured macroscopic of osteoid osteoma (Figure 3). On CT film after that showed the tumor removed completely (Figure 4) and post-operative anapath result confirmed this is osteoid osteoma, consistent with preoperative diagnosis. The patient is completely painless after surgery without using painkillers, discharged after 3 days. Follow-up after 6 weeks of surgery, the patient is out of pain, gains weight, walks normally.

In conclusion, ankle arthroscopy is a less invasive surgical method, appropriate to handle the tumor injury in the ankle joint, especially the tumors inside or beside the joint and under the cartilage. The advantages include:

- Be able to explore the whole ankle joint and related lesions by 2 incisions about $0.5 \mathrm{~cm}$ to make portals, especially valuable in cases of previous surgical interventions.

- The surgery time is shortened, technically not too complicated, it is worth in both diagnostic and treatment.

- Post-operative rehabilitation is simple, and minimizes risks such as infection, tough ankle joints, relative to open surgery.

- Almost absolute advantages over open surgery in the case of inside-joint or under-cartilage injuries.

\section{REFERENCES}

1. Jackson RP, Reckling FW, Mantz FA. Osteoid osteoma and osteoblastoma. Similar histological lesions with different natural histories. Clin Orthop Relat Res. 1977;128:303. PMid:598169

2. Greenspan A, Benign bone-forming lesions: osteoma, osteoid osteoma, and osteoblastoma. Clinical, imaging, pathologic, and differential considerations. Skeletal Radiol. 1993 Oct;22(7):485-500. https://doi.org/10.1007/BF00209095 PMid:8272884

3. Jaffe HL. Osteoid osteoma of bone. Radiology. 1935;45:319. https://doi.org/10.1148/45.4.319

4. Pikoulas C, Mantzikopoulos G, Thanos L, et al. Unusually located osteoid osteomas. Eur J Radiol, 1995;20:120125. https://doi.org/10.1016/0720-048X(95)00636-5

5. Snow SW, Sobel M, DiCarlo EF, Thompson FM, Deland JT. Chronic ankle pain caused by osteoid osteoma of the neck of the talus. Foot Ankle Int 1997;18(2):98-101. https://doi.org/10.1177/107110079701800211 PMid:9043883

6. Assoun J, Richardi J, Railhac JJ. Osteoid osteoma: MR imaging versus CT. Radiology 1994;191:217-23. https://doi.org/10.1148/radiology.191.1.8134575 PMid:8134575

7. Spouge AR, Thain LMF. Osteoid osteoma: MR imaging revisited. Clin Imaging, 2000;24:19-27. https://doi.org/10.1016/S0899-7071(00)00157-1

8. Goldman AB, Schneider R, Pavlov H. Osteoid osteomas of the femoral neck: report of four cases evaluated with isotopic bone scanning, CT and MR imaging. Radiology, 1993;186:227-32. https://doi.org/10.1148/radiology.186.1.8416569 PMid:8416569

9. Kayser $F$, Resnick D, Haghighi $P$, et al. Evidence of the subperiosteal origin of osteoid osteomas in tubular bones: analysis by CT and MR imaging. AJR Am J Roentgenol, 1998;170:609-614. https://doi.org/10.2214/ajr.170.3.9490939 PMid:9490939

10. Ebrahim FS, Jacobson JA, Lin J, et al. Intra-articular osteoid osteoma: sonographic findings in three patients with radiographic, CT and MR imaging correlation. AJR Am J Roentgenol, 2001;177:1391-1395. https://doi.org/10.2214/ajr.177.6.1771391 PMid:11717092

11. Allen SD, Saifuddin A. Imaging of intra-articular osteoid osteoma. Clin Radiol. 2003 Nov;58(11):845-52. https://doi.org/10.1016/S0009-9260(03)00213-7

12. Costa FM, Canella C. The usefulness of chemical-shift magnetic resonance imaging for the evaluation of osteoid osteoma. Radiol Bras. 2018 May-Jun;51(3):156-61. https://doi.org/10.1590/0100-3984.2017.0037 PMid:29991836 PMCid:PMC6034728 
13. Gunes T, Erdem M, Sen C, Bilen E, Yeniel K. Arthroscopic removal of a subperiosteal osteoid osteoma of the talus. J Am Podiatr Med Assoc 2007;97(3):238-43. https://doi.org/10.7547/0970238 PMid:17507536

14. Yercan HS, Okcu G, Ozalp T. Arthroscopic removal of the osteoid osteoma on the neck of the talus. Knee Surg Sports Traumatol Arthrosc 2004;12(3):246-55. https://doi.org/10.1007/s00167-003-0413-4 PMid:14530848

15. Ikegami M, Matsumoto T. Anterior Impingement Syndrome of the Ankle Caused by Osteoid Osteoma in the Talar Neck Treated with Arthroscopy and 3D C-Arm-Based Imaging. Case Rep Orthop. 2017. https://doi.org/10.1155/2017/2171627

16. Dimnjaković $D$, Bojanić I, et al. Periarticular osteoid osteoma of the ankle: a report of nine arthroscopically treated patients. J Foot Ankle Surg. 2015 Jan-Feb;54(1):89-93. https://doi.org/10.1053/j.jfas.2014.09.051 PMid:25459092

17. David $P$, Legname $M$, Dupond $M$. Arthroscopic removal of an osteoid osteoma of the talar neck. Orthop Traumatol Surg Res. 2009 Oct;95(6):454-7. https://doi.org/10.1016/j.otsr.2009.05.003 PMid:19740714

18. Banerjee $D$, Eriksson $K$, Morris H. Arthroscopically treated intraarticular osteoid osteoma in the ankle-a report of 3 cases. Acta Orthop. 2005 Oct;76(5):721. https://doi.org/10.1080/17453670510041826 PMid:16263621

19. Yercan HS, Okcu G, Ozalp T, Osiç U. Arthroscopic removal of the osteoid osteoma on the neck of the talus. Knee Surg Sports Traumatol Arthrosc. 2004 May;12(3):246-9. https://doi.org/10.1007/s00167-003-0413-4 PMid: 14530848

20. Resnick RB, Jarolem KL, et al. Arthroscopic removal of an osteoid osteoma of the talus: a case report. Foot Ankle Int. 1995 Apr;16(4):212-5. https://doi.org/10.1177/107110079501600409 PMid:7787980

$\diamond \diamond \diamond \diamond \diamond \diamond \diamond$

http://www.ejgm.co.uk 